\title{
The categorization effect in hedonic contrast: Experts differ from novices
}

\author{
Lauren M. Rota And Debra A. Zellner \\ Montclair State University, Montclair, New Jersey
}

\begin{abstract}
Test stimuli are rated as less "good" when they follow very good context stimuli than when they are presented alone. This diminution in rating is called hedonic contrast. Contrast is attenuated if the context and the test stimuli are perceived as being in different categories. Because experts use as their basic-level categories what are the subordinate levels for novices, they will categorize when novices do not. Therefore, in the following studies, both experts and novices showed hedonic contrast when attractive context orchids preceded more neutral test orchids. However, only the novices showed hedonic contrast when attractive context irises preceded the test orchids. Novices viewed the irises and the orchids as "flowers" and therefore members of the same category, resulting in contrast. Experts, however, viewed the irises and the orchids as being in different categories; therefore, hedonic contrast did not occur.
\end{abstract}

People categorize things at different levels. The levels are usually referred to as superordinate, basic, and subordinate. A basic category is one in which objects are recognized most rapidly and into which adults spontaneously classify objects (Rosch, Mervis, Gray, Johnson, \& Boyes-Braem, 1976). For biological categories (which is what we will use in the following studies), such as trees, "tree" would be the basic category for most urban people, "plant" would be superordinate, and "maple" would be subordinate (Rosch et al., 1976). But experts and novices have different basic categories; what is an expert's basic level is a novice's subordinate level (see, e.g., Johnson \& Mervis, 1997; Tanaka \& Taylor, 1991). Experts divide stimuli into many more categories in their area of expertise than do novices.

It has been suggested that this difference in categorization between novices and experts can result in different context effects in the two groups. Here, we examine the effect of context on hedonic evaluations. The presentation of context stimuli can result in the hedonic ratings of subsequently presented test stimuli moving toward the ratings of the context stimuli (hedonic assimilation). For example, good context stimuli presented before a test stimulus can cause that test stimulus to be rated as more hedonically positive than it would otherwise be. On the other hand, the presentation of context stimuli can result in the hedonic ratings of subsequently presented test stimuli moving away from those of the context stimuli (hedonic contrast). For example, good context stimuli presented before a test stimulus can cause that test stimulus to be rated as less hedonically positive. Both assimilation and contrast have been reported.

One model that attempts to explain why assimilation occurs sometimes and contrast at other times is the inclu- sion/exclusion model of Schwarz and Bless (1992). According to their model, assimilation effects occur when subjects regard the context and test stimuli as belonging to the same category (inclusion), whereas contrast occurs if the context and test stimuli are viewed as coming from separate categories (exclusion). Based on their model, they "expect contrast effects to be more likely to emerge in judgments made by experts than in judgments made by novices" (Schwarz \& Bless, 1992, p. 233). Experts, having more categories, should show more contrast, because any two stimuli in their area of expertise will probably be in separate small subordinate categories (exclusion). Novices, on the other hand, should show more assimilation, because they include many stimuli in the same large basic category (one that is superordinate for experts).

Although most of the studies used to support this model investigate the effect of inclusion or exclusion of an exemplar on the rating of a category, Wanke, Bless, and Igou (2001) have shown the effect of categorization of one exemplar on another. They found that the presentation of a well-liked politician of a particular political party resulted in decreased favorability ratings for other politicians of the same party (i.e., resulted in contrast) unless subjects were told that the politicians were from the same party. When subjects were told to categorize the contextual good politician with the test politicians, the good context stimulus did not cause contrast in the favorability ratings of the test politicians. Contrast was seen only when the common category membership of the context and test stimuli was not emphasized. A similar effect occurred in a second study, in which a good toaster of a specific brand reduced the favorability ratings of a less good toaster of that same brand only when the brand of the two toasters was not

D. A. Zellner, zellnerd@mail.montclair.edu 
made obvious. So again, when subjects were told that the context and test stimuli were from the same category, contrast did not occur.

These findings support what Schwarz and Bless (1992) suggest: Experts should show more contrast than do novices. In particular, novices should not show any contrast if they judge, for example, how attractive they found some moderately attractive trees after they judge some attractive trees, because they will view them all as trees. However, experts should show contrast if the context and test trees are from different categories (e.g., maple vs. oak) but not when they are all from the same category (e.g., all maples).

This prediction is the opposite of what Fechner said should happen in the discussion of hedonic contrast in his 1898 book Vorschule der Ästhetik II. According to BeebeCenter (1932/1965), Fechner believed that hedonic contrast would occur only if certain conditions were fulfilled, including that "the two factors had to bear a certain resemblance to each other" (pp. 222-223). That is, the stimulus to be judged and the context stimuli had to resemble one another or be from the same category of stimuli.

Our previous work on categorization's effects on hedonic contrast supports Fechner's view. We (Dolese, Zellner, Vasserman, \& Parker, 2005; Zellner, Rohm, Bassetti, \& Parker, 2003) demonstrated that when subjects were instructed to consider the context and test stimuli to be in the same category, hedonic contrast occurred, but when subjects were instructed to consider the stimuli to be in different categories, contrast was attenuated. So, for example (Zellner et al., 2003), pictures of North American birds that followed pictures of brightly colored tropical birds were judged less attractive by subjects who were told that all of the stimuli were "birds" than by subjects who were told that the first set was "tropical birds" and the second set was "North American birds." Similar results were found with judgments of liking for juices (Zellner et al., 2003) and paintings (Dolese et al., 2005), and in studies in which subjects formed their own categories of coffees and beers (Zellner, Kern, \& Parker, 2002).

We would thus expect that since most people are novices and categorize all trees as "trees," a set of attractive context trees would result in reduced hedonic ratings of subsequently presented test trees (hedonic contrast). It should not matter what kind of trees the context and test trees are. So if the test trees are maples, the degree of hedonic contrast should not depend on whether the context trees are maples or oaks.

However, a different outcome should occur with people who are tree experts, since what serves as a basic category for an expert is different from that for a novice. Therefore, we would predict that for tree experts, hedonic contrast should occur when both the context and test trees are maples but not when the context trees are oaks and the test trees are maples.

Clearly, our predictions concerning the effect of categorization on contrast differ from those of Schwarz and Bless (1992). Both models agree that contrast occurs when subjects make comparisons, but they disagree as to when comparisons occur. Schwarz and Bless think comparisons occur when contrast and test stimuli are in different cat- egories, and we believe they occur only when they are in the same category.

The reason for this difference in the models stems from the fact that Schwarz, Bless, and their colleagues' subjects judge stimuli that are unfamiliar to many of them and about which they have little information. For example, many people who do not keep up with politics would know little about politicians named by an experimenter. They would therefore have little information with which to make a favorability judgment, and would probably have difficulty doing so. That situation is very different from our studies, in which viewing a colored picture of a flower is sufficient for a novice to make an attractiveness judgment.

Experts are very familiar with stimuli in their area of expertise and have much information on which to base a judgment. Here, we study the occurrence of contrast among experts and novices in a situation in which both groups will have enough information with which to make judgments easily. In this way, we can be sure that any effects seen are the result of differences in categorization and not in the ability to make judgments.

The following experiments use flowers as stimuli and investigate the effect of categorization on hedonic contrast by testing flower novices (Experiment 1) and flower experts (Experiment 2). Since the basic taxonomic level for experts is the subordinate level for novices, we expect experts to separate irises and orchids into two categories, whereas novices should perceive them as being in one category (flowers). We believe that this should result in comparisons and contrast occurring for novices when either attractive irises or orchids precede less-attractive test orchids. Experts, however, should only compare orchids with other orchids, and show contrast when attractive orchids precede the test orchids but not when attractive irises do. Therefore, experts should show less contrast than novices because of their use of more and smaller categories.

Schwarz and Bless (1992) would predict quite a different outcome. Their inclusion/exclusion model predicts that contrast will occur for the experts but not the novices. And it should occur among the experts only when the attractive irises, rather than the attractive orchids, precede the test orchids, such that the context and test stimuli are in different categories.

\section{EXPERIMENT 1}

This experiment investigates the effect of categorization on hedonic contrast in flower novices. The subjects used in this experiment were unable to use the subordinate level of taxonomy for flowers (i.e., they were unable to correctly identify the irises and orchids used in the experiment as such). Their basic category was "flower." Therefore, subjects in both the group that judged attractive irises before test orchids and the group that judged attractive orchids before the test orchids should put the attractive context flowers and the test flowers in the same category. We predict hedonic contrast will occur for both groups. The inclusion/exclusion model would predict that hedonic contrast will occur in neither group. 


\section{Method}

Subjects. Forty-three volunteers (undergraduates, graduate students, staff, and faculty) from Montclair State University served as subjects. All were flower novices; none of them had knowledge of or experience with flowers that would qualify them as flower experts. Thirty-four of the subjects were female and 9 were male. The subjects' mean age was 24.3 years.

Materials. Colored photographs of flowers cut out of books were pasted on $17.8 \times 25.3 \mathrm{~cm}$ white poster board. Seven pictures were of irises (context irises), those rated most attractive out of 9 in preliminary testing. Another 7 pictures were of orchids (context orchids), those rated most attractive out of 22 in preliminary testing. Finally, 6 pictures were of orchids (test orchids) rated as neutral or only slightly attractive in preliminary testing. ${ }^{1}$

Procedure. All of the subjects were told that they would be rating pictures of flowers. The subjects were randomly assigned to one of three groups: IO, OO, and C. People in Group IO (iris-orchid, $n=$ 13) rated a set of seven attractive context irises prior to rating the set of six test orchids. Those in Group OO (orchid-orchid, $n=15$ ) rated a set of seven attractive context orchids prior to rating the set of six test orchids. Group C (control, $n=15$ ) rated only the test orchids.

Subjects were tested individually. The subjects in all of the groups rated the attractiveness of each flower on a 201-point bipolar hedonic scale, on which +100 represented "the most attractive flower imaginable," -100 represented "the most unattractive flower imaginable," and 0 indicated a flower that was "neither attractive nor unattractive." They inspected one picture at a time (stimulus sequences randomized within sets) and announced their ratings.

Following the ratings of the flowers, the subjects filled out a questionnaire asking them their gender, age, and occupation. In order to assess their knowledge of flowers, they were also asked to indicate how many types of flowers they saw, what kinds of flowers they saw (e.g., "Were they all tulips?"), and if the flowers they saw were arranged in a particular order. In addition, they were asked if they belonged to a garden club, had taken classes in flower arranging, or had ever worked in a flower shop. They also were asked if they considered themselves to be flower experts.

\section{Results}

All of the subjects were novices, since none of them indicated any knowledge of flowers or correctly identified the number of types of flowers they saw, the type(s) of flower(s) they saw, or the sequence in which the types of flowers were presented. None were members of a garden club, nor had any taken classes in flower arranging or worked in a flower shop. None of them considered themselves to be flower experts.

For each subject in Group IO, we calculated the average rating for the context irises $(M=53.7, S D=16.5)$, and for each subject in Group OO, we calculated the average rating for the context orchids $(M=35.8, S D=28.6)$. Although the context irises were judged more attractive than the context orchids, the difference in attractiveness was not significant, according to a Mann-Whitney test $\left(n_{1}=\right.$ $13, n_{2}=15 ; U_{1}=137, U_{2}=58 ; p=.072$ ). The value of the effect size indicator Cliff's $d$ (Cliff, 1993) was .40 . See Table 1.

For each subject, in each group, we calculated the average rating assigned to flowers in the test orchid set. A Kruskal-Wallis test revealed that the attractiveness ratings of the test orchids differed among the groups $[H(2)=10.4$, $\left.p<.006, \eta^{2}=.24\right]$ (Marascuilo \& McSweeney, 1977). Steel-Dwass-Critchlow-Fligner multiple comparisons (Hollander \& Wolfe, 1999) showed that Groups IO ( $M=$
4.7, $S D=32.8)$ and $\mathrm{OO}(M=0.3, S D=28.2)$ rated the test orchids as less attractive than did Group C $(M=36.4$, $S D=27.4)(p<.056$ and .006 , respectively; Cliff's $d=$ .51 and .66 , respectively). There was no significant difference in the ratings of the test orchids by Groups IO and OO $(p>.83$; Cliff's $d=.13)$. See Table 1 .

\section{Discussion}

The results support our idea that viewing the context and test stimuli as being in the same category results in hedonic contrast. As expected, we found hedonic contrast in Group OO, which rated attractive context orchids before the test orchids and in Group IO, which rated the attractive context irises before the test orchids. Although the irises and orchids are in different subordinate categories, the novices in this study did not regard them that way. Because their basic category was "flowers," they viewed the context irises and the test orchids as being in the same category. This resulted in hedonic contrast in both Group IO and Group OO, in which attractive context flowers preceded the test orchids.

\section{EXPERIMENT 2}

Placing flowers into subordinate categories is likely to occur among experts. So we would expect experts to show hedonic contrast when attractive orchids precede the test orchids, but not when attractive irises precede the test orchids. The inclusion/exclusion model would predict the opposite.

\section{Method}

Subjects. Thirty volunteers from flower shops, garden clubs, and other horticultural organizations served as subjects. All of the subjects had training and experience working with flowers. Twenty-one of the subjects were female and 9 were male. The subjects' mean age was 43.9 years.

Materials. The materials used were the same materials used in Experiment 1.

Procedure. The procedure was the same as described in Experiment 1 . The subjects were randomly assigned to the three groups $(n=10$ each).

\section{Results}

All 30 subjects were experts. They indicated that they had knowledge of flowers. They all correctly identified the number of types of flowers they saw, the type(s) of flower(s), and the sequence in which the types of flowers were presented. All of the subjects had taken classes in flower arranging, had worked in a flower shop, and/or had been members of a garden club.

Table 1

Mean Ratings and Standard Deviations of Context and Test Flowers for the Three Groups of Novices

\begin{tabular}{|c|c|c|c|c|}
\hline \multirow[b]{2}{*}{ Group } & \multicolumn{2}{|c|}{$\begin{array}{c}\text { Context Flowers } \\
\text { (Irises or Orchids) }\end{array}$} & \multicolumn{2}{|c|}{ Test Orchids } \\
\hline & $M$ & $S D$ & $M$ & $\overline{S D}$ \\
\hline $\mathrm{IO}$ & 53.7 & 16.5 & 4.7 & 32.8 \\
\hline $\mathrm{OO}$ & 35.8 & 28.6 & 0.3 & 28.2 \\
\hline $\mathrm{C}$ & - & - & 36.4 & 27.4 \\
\hline
\end{tabular}


For each subject in Group IO, we calculated the average rating for the context irises $(M=61.5, S D=26.8)$ and for each subject in Group OO, we calculated the average rating for the context orchids $(M=46.1, S D=14.0)$. Although the context irises were judged somewhat more attractive than the context orchids, the difference in attractiveness was not significant, according to a Mann-Whitney test $\left(n_{1}=10, n_{2}=10 ; U_{1}=35, U_{2}=65 ; p=.28\right.$; Cliff's $d=.30)$. See Table 2 .

For each subject, in each group, we calculated the average rating assigned to flowers in the test orchid set. A Kruskal-Wallis test revealed that the attractiveness ratings of the test orchids differed significantly among the groups $\left[H(2)=8.8, p<.02, \eta^{2}=.30\right]$ (Marascuilo \& McSweeney, 1977).

Steel-Dwass-Critchlow-Fligner multiple comparisons (Hollander \& Wolfe, 1999) showed that Group OO ( $M=$ 14.0, $S D=39.2)$ rated the test orchids as less attractive than did both Group C $(M=52.8, S D=18.8)(p<.02$; Cliff's $d=.70)$ and Group IO $(M=59.2, S D=25.1)$ $(p<.04$; Cliff's $d=.64)$. However, there was no significant difference in the ratings of the test orchids by Groups $\mathrm{IO}$ and $\mathrm{C}(p>.81$; Cliff's $d=.16)$. See Table 2 .

\section{Discussion}

Again, the results support our prediction that hedonic contrast should occur only when the context and test stimuli are viewed as being from the same category. Like the novices, the experts in Group OO (who rated attractive context orchids before the test orchids) showed contrast. But unlike the novices, the experts in Group IO did not show hedonic contrast. Because their basic-level category consisted of "irises" and "orchids," experts viewing the attractive irises before the test orchids did not compare them. Putting the context and the test flowers into different categories resulted in elimination of hedonic contrast for the experts and in their rating the test orchids equivalently to Group C.

It should be noted that categorization of the context flowers (irises) and the test flowers (orchids) by the experts in Group IO resulted in the total elimination of hedonic contrast. That did not occur in previous studies in which categorization was produced through verbal instructions telling the subjects that the context and test stimuli were from different categories (Dolese et al., 2005; Zellner et al., 2003). The fact that hedonic contrast was reduced but not eliminated by categorization instructions indicates that the subjects in the previous studies were probably still using their natural basic categories as well as the subor-

Table 2

Mean Ratings and Standard Deviations of Context and Test Flowers for the Three Groups of Experts

Context Flowers

(Irises or Orchids) Test Orchids

\begin{tabular}{cccccc} 
& \multicolumn{2}{c}{ (Irises or Orchids) } & & \multicolumn{2}{c}{ Test Orchids } \\
\cline { 2 - 3 } \cline { 5 - 6 } Group & $M$ & $S D$ & & $M$ & $S D$ \\
\hline IO & 61.5 & 26.8 & & 59.2 & 25.1 \\
OO & 46.1 & 14.0 & & 14.0 & 39.2 \\
C & - & - & & 52.8 & 18.8 \\
\hline
\end{tabular}

dinate ones we were suggesting to them. So, for example, although subjects were told in Zellner et al. (2003) that the context birds were tropical birds and the test birds were North American, they still compared the two categories of birds to some degree, because their basic category (as bird novices) was "birds." Thus, they saw the two kinds of birds as still being "birds" and therefore capable of being compared.

\section{GENERAL DISCUSSION}

These studies confirm Fechner's principle of hedonic contrast (Beebe-Center, 1932/1965) and our previous findings that categorization attenuates such contrast (Dolese et al., 2005; Zellner et al., 2002; Zellner et al., 2003). We believe this occurs because what categorization does in these situations is tell the subjects what things are to be compared, and comparison results in contrast (Stapel \& Winkielman, 1998). Among the experts in Experiment 2 for whom context irises preceded test orchids, hedonic contrast was eliminated. Experts perceived the two kinds of flowers to be in different categories and did not compare them. On the other hand, for the novices in Experiment 1, the two kinds of flowers were all members of their basic category of flowers and were thus compared, resulting in hedonic contrast.

So why do Schwarz and Bless (1992) predict more contrast in experts? We believe that it is because of the stimuli they use. The unfamiliarity of the stimuli and the subjects' lack of sufficient information to make a judgment about them result in the use of the category itself as an interpretation frame (see Stapel \& Winkielman, 1998; Wanke et al., 2001). In this situation, the category information will be used to help subjects make a hedonic judgment about the stimulus. So, for example, for a novice, knowing that a particular politician is in the same political party as a well-known, well-liked politician will allow the two politicians to be compared, causing contrast, but only if both politicians are familiar to the subject. However, if the "test" politician is unknown to the subject, then information about the political party will provide information with which to judge the unknown politician, causing the favorability rating to assimilate toward that of the wellknown politician.

An expert, however, will have sufficient information to make a judgment about the lesser politician without being told that this politician is in the same party as the well-known politician. In this case, the same-party categorization will result in a comparison between the two politicians, and therefore, contrast. Because experts should never feel the need for more information about stimuli with which they are expert, the use of a category as an interpretation frame should not occur, and within-category comparisons should result in more contrast among experts than among information-seeking novices, as Schwarz and Bless (1992) predicted.

Therefore, how much contrast one sees in experts relative to novices will depend on the judgment being made. If both experts and novices have enough information to comfortably make the judgment they are asked to make 
(as in our studies), the experts will show less contrast than the novices. This will occur because the experts have more categories; this results in fewer items being in the same category, fewer items being compared, and ultimately, in less comparison contrast. However, in situations in which novices do not feel as though they have enough information to make a judgment, experts might show more contrast, because the novices are using the category information to help them make their judgment rather than to define the range of items to be compared.

\section{AUTHOR NOTE}

We thank Scott Parker for his help with the statistical analyses and Scott Parker, John Wixted, and three anonymous reviewers for their comments on previous versions of the manuscript. We also thank the generous volunteers from the Presby Iris Gardens, Master Gardeners of Essex, and from the following flower shops: Accents with Flowers, Anderson's Flowers Inc., Buds for You, The Garden Shop, and Kabloom, all of Montclair, NJ, Colony Florist and Gifts of Franklin Lakes, NJ, and Wyckoff Florist and Gifts of Wyckoff, NJ. Correspondence concerning this article should be addressed to D. A. Zellner, Department of Psychology, Montclair State University, Montclair, NJ 07043 (e-mail: zellnerd@ mail.montclair.edu).

\section{REFERENCES}

Beebe-Center, J. G. (1965). The psychology of pleasantness and unpleasantness. New York: Russell \& Russell. (Original work published 1932)

CLIFF, N. (1993). Dominance statistics: Ordinal analyses to answer ordinal questions. Psychological Bulletin, 114, 494-509.

Dolese, M. J., Zellner, D. A., Vasserman, M., and Parker, S. (2005). Categorization affects hedonic contrast in the visual arts. Bulletin of Psychology \& the Arts, 5, 21-25.

Fechner, G. T. (1898). Vorschule der Ästhetik II (2nd ed.). Leipzig: Breitkopf \& Härtel.

Hollander, M., \& Wolfe, D. A. (1999). Nonparametric statistical methods (2nd ed.). New York: Wiley.

Johnson, K. E., \& Mervis, C. B. (1997). Effects of varying levels of expertise on the basic level of categorization. Journal of Experimental Psychology: General, 126, 248-277.

Marascuilo, L. A., \& McSweeney, M. (1977). Nonparametric and distribution-free methods for the social sciences. Monterey, CA: Brooks/Cole.

Rosch, E., Mervis, C. B., Gray, W. D., Johnson, D. M., \& BoyesBraem, P. (1976). Basic objects in natural categories. Cognitive Psychology, 8, 382-439.

SChWARZ, N., \& Bless, H. (1992). Constructing reality and its alternatives: An inclusion/exclusion model of assimilation and contrast effects in social judgment. In L. L. Martin and A. Tesser (Eds.), The construction of social judgments, pp. 217-245. Hillsdale, NJ: Erlbaum.

Stapel, D. A., \& Winkielman, P. (1998). Assimilation and contrast as a function of context-target similarity, distinctness, and dimensional relevance. Personality \& Social Psychology Bulletin, 24, 634-646.

TANAKa, J. W., \& TAYlor, M. (1991). Object categories and expertise: Is the basic level in the eye of the beholder? Cognitive Psychology, 23, 457-482.

Wanke, M., Bless, H., \& Igou, E. R. (2001). Next to a star: Paling, shining, or both? Turning interexemplar contrast into interexemplar assimilation. Personality \& Social Psychology Bulletin, 27, 14-29.

Zellner, D. A., Kern, B. B., \& Parker, S. (2002). Protection for the good: Subcategorization reduces hedonic contrast. Appetite, 38, 175-180.

Zellner, D. A., Rohm, E. A., Bassetti, T. L., \& Parker, S. (2003). Compared to what? Effects of categorization on hedonic contrast. Psychonomic Bulletin \& Review, 10, 468-473.

\section{NOTE}

1. Eight subjects who did not participate in the studies rated a set of 31 flowers (22 orchids and 9 irises), which were presented to each subject in random order. Subjects rated them on the 201-point bipolar hedonic scale that was used in the studies. The set was preselected to contain orchids that had a broad range of attractiveness and irises that were very attractive. The 7 most attractive orchids $(M=48.4)$ and most attractive irises $(M=46.0)$ were both rated as more attractive than the 6 orchids chosen to be the test orchids $(M=5.8)$.

(Manuscript received August 29, 2005; revision accepted for publication May 30, 2006.) 